\title{
New record of viviparity for the dominant benthic invertebrate Exogone hebes (Polychaeta: Syllidae) from the Grand Banks of Newfoundland
}

\author{
Patricia Pocklington* and Michael S. Hutcheson**
}

MacLaren Plansearch Limited Suite 1020, Cogswell Tower, 2000 Barrington Street, Halifax, Nova Scotia B3J 3K1, Canada

\begin{abstract}
The dominant infaunal benthic invertebrate on the Grand Banks of Newfoundland, Exogone hebes, is viviparous. This is the first recorded case of such development for this genus. Scanning electron microscopy documents the presence of fully differentiated juveniles within modified segments. On separation from the female, each juvenile was 7 segments long, had a fully developed antenna, pharynx, 5 setigerous segments and a pygidium with anal cirri. The juveniles were extruded via the nephridial pores. Previously, external brooding of eggs and larvae has been described for this species. Incubating females were observed from March to November with a spawning maximum in spring (May). These new observations suggest a possible reason for the obvious ecological success of the species in one of the colder parts of its range.
\end{abstract}

\section{INTRODUCTION}

Benthic invertebrate assemblages of the continental shelf of eastern North America from Virginia to Newfoundland are numerically dominated by polychaete worms (Boesch et al., 1976; Maurer et al., 1976; Maurer and Leathem, 1980; Hutcheson et al., 1981). More than $50 \%$ of the individuals of the macrobenthos on the Grand Banks of Newfoundland consist of polychaetes with 7 of the 10 most abundant species being polychaetes. The dominant species are generally members of families consisting of small individuals, often Syllidae and Spionidae. Maurer and Leathem (1980) suggest that smaller fish may prey heavily on these organisms and that the smaller forms may play a larger role than previously attributed in the transfer of energy between benthic communities and groundfish.

A newly recorded mode of development for the dominant species, Exogone hebes, on the Grand Banks is described in this paper as are aspects of its annual

\footnotetext{
- Nova Scotia Museum, 1747 Summer St., Halifax, Nova Scotia B3H 3A6, Canada

*Atlantic Oceanics Company Ltd., 46 Fielding Ave., Dartmouth, Nova Scotia B3B 1E4, Canada
}

reproductive cycle. This small ( $\leqslant 10 \mathrm{~mm}$ total length) syllid (subfamily Exogoninae) was the most frequently encountered $(35.9 \%$ of time) and most abundant (mean number of individuals $=220 \mathrm{~m}^{-2}$ ) species. It occurs from Delaware to the Gulf of St. Lawrence (Webster and Benedict, 1884; Pettibone, 1963; Kinner and Maurer, 1978; Maurer and Leathem, 1980), in W. Greenland (Wesenberg-Lund, 1947, 1950a), in the waters of Denmark (Wesenberg-Lund, 1950b), Ireland (Southern, 1914), English Channel (Gibbs, 1968), and Baie St. Martin, France (Mesnil and Caullery, 1917).

This paper documents the first recorded instance of viviparity in Exogone hebes. Viviparity in this case is defined as the condition where the fertilized eggs are retained within the mother while they cleave and differentiate (Schroeder and Hermans, 1975). Previous work on this species describes mature males with swimming setae and mature females with eggs attached to the parapodia (Mesnil and Caullery, 1917). Viviparous development has been documented in several families of polychaetes (Hartman, 1951; Schroeder and Hermans, 1975). In the family Syllidae, it has been observed only 4 times (Caullery and Mesnil, 1916; Augener, 1929, cited in Hartman, 1951; and McIntosh, 1879 and Goodrich, 1900, cited in Schroeder and Hermans, 1975). 


\section{METHODS}

A seasonal sampling program was carried out on the Grand Banks of Newfoundland (Fig. 1) from March 1980 through February 1981. The macrobenthos at 14 stations was sampled every 2 mo with replicate $0.1 \mathrm{~m}^{2}$ Van Veen grabs and 2 epibenthic sled tows. Ten of the stations were from a localized area on the northeast Grand Bank. Samples were elutriated onboard ship, preserved in $10 \%$ hexamethylenetetramine buffered formalin and returned to the laboratory where they were sieved on a $0.47 \mathrm{~mm}$ sieve. Individual taxa were briefly rinsed with distilled water, blotted and weighed, then stored in $70 \%$ ethanol. For Exogone hebes, a random subsample of approximately 100

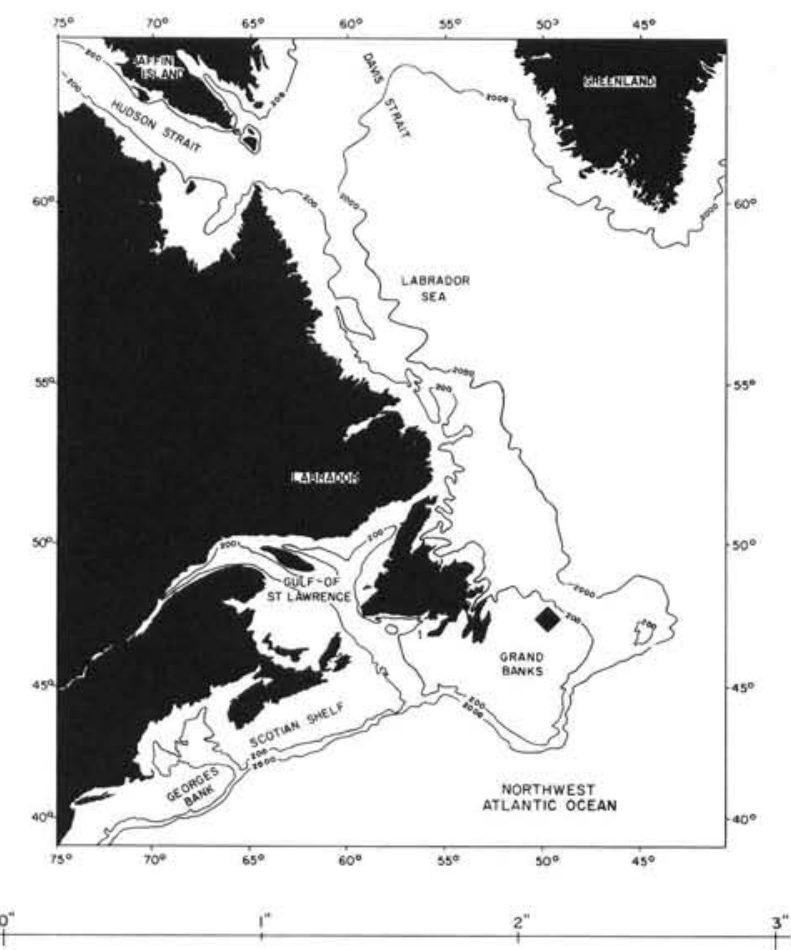

Fig. 1. Grand Banks of Newfoundland showing primary sampling area $(\bullet)$

worms was taken from each sampling period's group, and individual total lengths were measured to the nearest $\mathrm{mm}$. The majority of individual E. hebes $(2,836$ of 3,242 specimens) obtained as part of the sampling program were collected from the localized area. The sediment at these stations, depth 70 to $90 \mathrm{~m}$, ranged from fine sand to gravel, with $E$. hebes prevalent on the coarse-grained bottoms.

In addition to identification and enumeration of Exogone hebes from these samples, the reproductive state of each individual was noted. The categories were: atokes, non-reproductive individuals displaying no deviation from original description given by Webster and Benedict (1884); male epitokes, individuals displaying all stages of additional setal development in the reproductive segments from the 11th setiger onward; and mature females, individuals having mature reproductive segments (Setiger 17 onward). Individuals less than $5 \mathrm{~mm}$ long were considered reproductively immature as no epitokous individuals were observed in that size range.

Preserved female specimens were prepared for scanning electron microscopy by successive $20 \mathrm{~min}$ washings in $70 \%, 90 \%$ and absolute ethyl alcohols. They were then put in isoamyl acetate and critical-point dried in carbon dioxide. The specimens were then placed on a SEM stub with double faced tape and put in a sputter coater where they were coated with goldpaladium. The prepared samples were scanned and photographed on a Cambridge-Stereo Scan S-150.

\section{RESULTS}

During identification and subsequent assignment to reproductive state of Exogone hebes, a considerable disparity with previously described development for this species became apparent. Mature females did not have externally brooded eggs or larvae; instead, the mature females displayed an enlargement of the reproductive segments to accommodate their internally developing young, some of which were in the process of being extruded. This enlargement began at Segment 18 and continued for 10 or 12 segments, the last few segments being unchanged.

The enlargement of each segment was accompanied by a corresponding enlargement of the segmental aperture, a feature indiscernable in atokous worms but conspicuous in the reproductive female (Fig. 2). The aperture was covered by a thin, parchment-like cap (Fig. 2) which appeared to tear off as the juvenile was about to emerge.

Incompletely differentiated juveniles within the coelom could be forced out the segmental aperture by applying a slight pressure on the enlarged segment. In many females, the juveniles were at a more advanced stage of development and were observed in the process of being released from the segment through the coelomoduct (Fig. 3). These juveniles were completely differentiated into 7 segments, with a fully developed antenna, pharynx, 5 setigerous segments and a pygidium with anal cirri (Fig. 3 and 4).

Mature females, after release of juveniles, could be identified by a modification of the ventral surface of the reproductive segments. These surfaces were roughened and wrinkled (Fig. 5), presumably as a result of contraction of the ventral surface after expul- 
sion of the juveniles. No larvae were observed at the scanning EM level within the spent segments.

Gravid females were present from March to November on the Grand Banks (Table 1). All stages of ventral modification in females occurred at every sampling period. The smallest proportion of individuals distinguishable as reproductively active females was present in March, and the greatest proportion in May. The abundance of females stabilized around $6 \%$ from July through November.

The largest percentage of individuals with swimming setae occurred in March (Table 1). These male epitokes disappeared entirely from the benthos during the summer and appeared again in November as newly developing epitokes. The swimming setae were shortest in November, being approximately $2 / 3$ the width of the body; however, in March the length of each bundle of setae was 3 times the width of the body.

\section{DISCUSSION}

Variety in modes of reproduction in marine invertebrates is well illustrated in the polychaetes (e.g. Thorson, 1950; Schroeder and Hermans, 1975). There are differences within a family, genus and even within a species. Thorson (1950) mentioned 15 species with more than one mode of development reported. For example, 1 species in the family Nereidae, Platynereis dumerilii, has 4 documented modes of reproduction. Two syllids, Syllis prolifera and Ehlersia sexoculata, have been observed to develop both oviparously and ovoviviparously (Mesnil and Caullery, 1917).

To illustrate the variations in development of congeneric species, the general features of development in several species of Exogone are presented in Table 2.

In Exogone naidina Oersted, sexually mature males

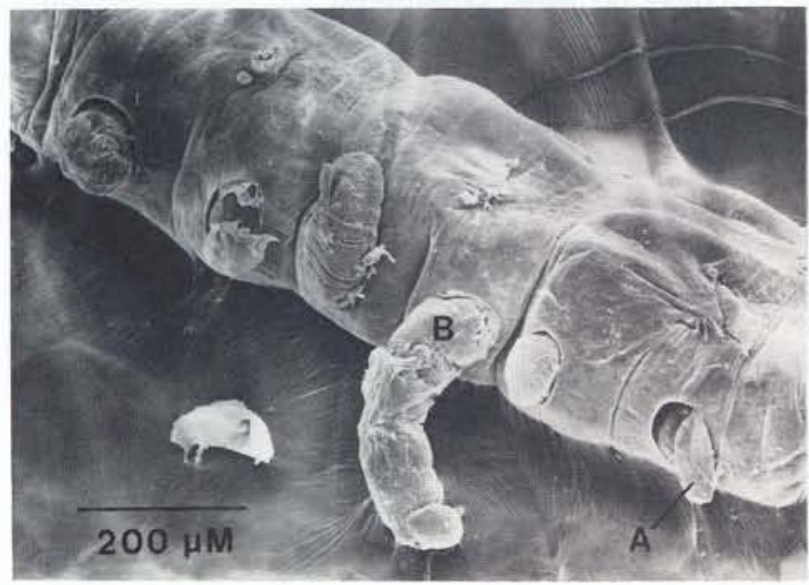

Fig. 2. Exogone hebes. Several segments from reproductive area showing enlarged segmental apertures with caps $(\mathrm{A})$ and emerging young (B) and females develop long swimming setae. Large eggs are passed through nephridia of the reproductive segments and attached to each parapodium. After the eggs are extruded and fertilized, the females lose their

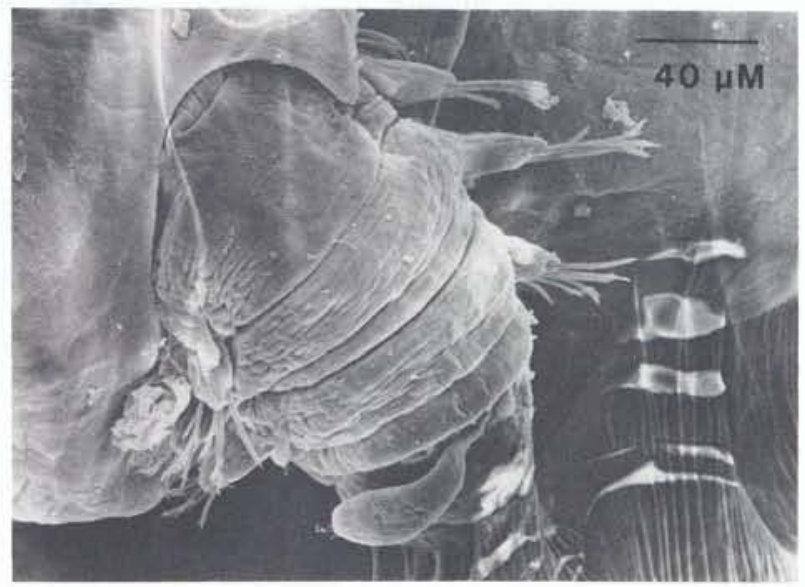

Fig. 3. Exogone hebes. Young emerging through segmental aperture

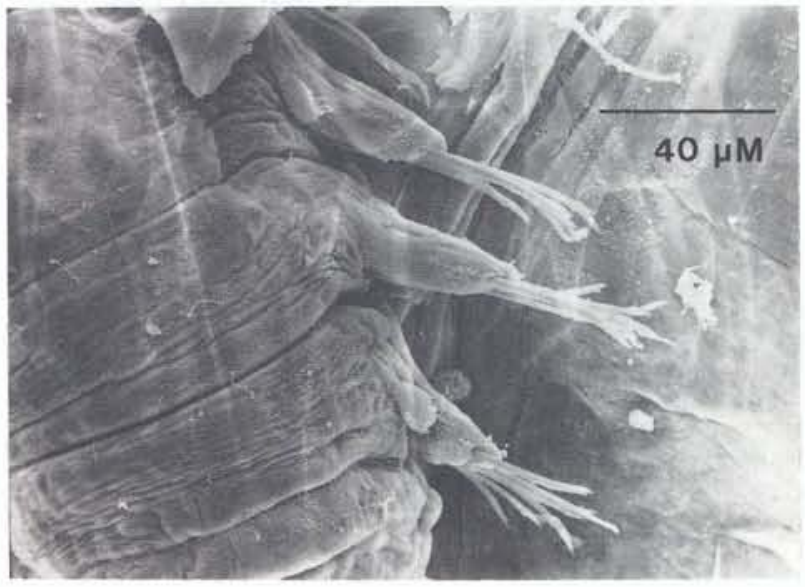

Fig. 4. Exogone hebes. Completely differentiated juvenile with diagnostic characteristics evident

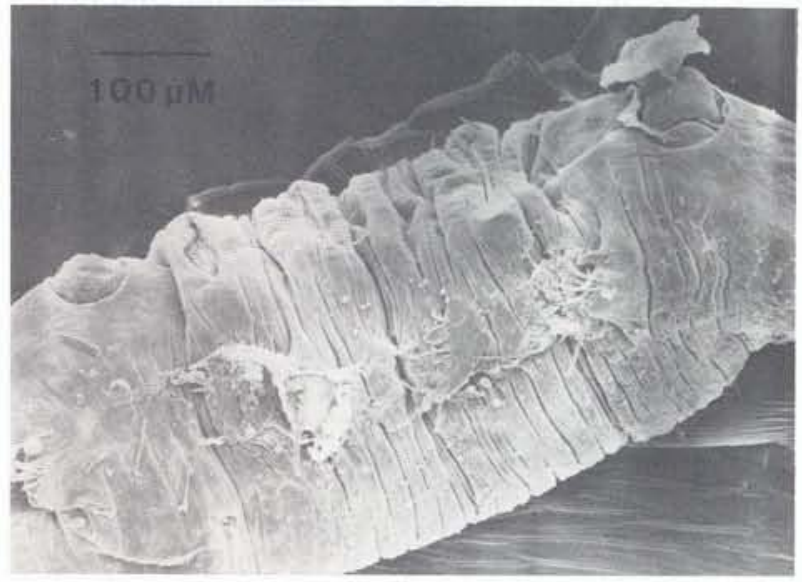

Fig. 5. Exogone hebes. Characteristic crenulation of ventral surface (facing up) of female after young are released 
Table 1. Seasonal changes in reproductive forms of Exogone hebes on the Grand Banks of Newfoundland

\begin{tabular}{|lcccc|}
\hline Month & $\mathrm{n}$ & $\begin{array}{c}\text { Aver. } \\
\text { density } \\
\left(\# \mathrm{~m}^{-2}\right)\end{array}$ & $\begin{array}{c}\text { Male } \\
\text { epitoke } \\
(\%)\end{array}$ & $\begin{array}{c}\text { Female } \\
\text { epitoke } \\
(\%)\end{array}$ \\
\hline March & 218 & 27.2 & 15.0 & 2.0 \\
May & 606 & 16.3 & 1.0 & 9.0 \\
July & 679 & 24.2 & 0 & 6.0 \\
Sept. & 419 & 18.2 & 0 & 5.7 \\
Nov. & 914 & 30.4 & 3.6 & 6.6 \\
\hline
\end{tabular}

swimming setae and sink to the bottom. There the larvae develop to miniature adults and are released to crawl on the bottom (Thorson, 1950). A study by Imajima (1966) further documents this process and describes a mature female with many juveniles attached at junctions of the parapodia with the body.

A similar procedure for fertilization and development of young occurs in Exogone verugera Claparède. This observation is supported by Pettibone (1963) and Wesenberg-Lund (1947). Blake and Dean (1973) however, collected specimens with eggs in a brood sac attached to the abdomen.

In Exogone dispar (Webster), the females produce large purplish eggs. These eggs or young may be attached to the body (Pettibone, 1963). We have observed a female taken in May from the Grand Banks with 2 large eggs per segment attached ventrally by a small peduncle close to the parapodia. Mature male and female epitokes have long swimming setae; these setae are lost by incubating females.

Development in $E$. hebes has been described for populations in Baie St. Martin, France (Mesnil and Caullery, 1917). Mature females had 2 eggs attached to each parapodium and males had swimming setae. Examination of large numbers of individuals of $E$. hebes from the Grand Banks of Newfoundland in this study produced no females with eggs or larvae attached to the parapodia. All fertilized females contained developing larvae within their coeloms or else had juveniles emerging from enlarged segments.
Mature males possessed swimming setae. Viviparity therefore occurs in E. hebes, thus adding this species to the list of polychaetes with more than one known method of development.

There was no fixed breeding season for Exogone hebes on the Grand Banks, as deduced from the yearround presence of incubating females. A spring spawning maximum occurs as epitokes bearing swimming setae disappear from the bottom and presumably ascend into the water column to spawn. The increased number of fertilized females in May reflects this spring spawning peak (Table 1). As the females did not have swimming setae, it is possible that the males do not go very far from the bottom. They may swarm collectively and spawn above the colony. No epitokous males were found in oblique and vertical zooplankton hauls taken in the upper portions of the water column at same time (Strong, 1981). Infrequently, dead, spent males were found in the grabs, which might indicate that the male dies after spawning.

Thorson (1950) suggested that the poecilogony observed in many polychaetes accounts for their cosmopolitan nature by permitting them to adjust their reproductive strategy to the demands of the environment. Exogone hebes on the Grand Banks exists in some of the coldest waters of its range (annual mean temperature of $-0.05{ }^{\circ} \mathrm{C}( \pm 0.57,1$ S.D. $)$ and range from approximately -1.46 to $2.12{ }^{\circ} \mathrm{C}$ ) (Mobil Oil Canada Ltd., unpubl.). Thorson (1950) correlated geographical distribution with mode of development and generalized that under polar and deep-sea conditions, polychaetes favor direct development from yolky eggs which are large relative to the size of the female (nonpelagic lecithotrophic development). Studies by Blake (1969), Chia (1970), Mileikovsky (1971), and Daly (1972) have since supported this observation. Curtis (1977) noted that of 35 species of benthic polychaetes off West Greenland for which reproductive modes were determined, 25 had direct developing lecithotrophic larvae. However, the relationship between latitude and development type may not be as distinct as previously thought. Complicating factors such as the size of the adult may affect the type of

Table 2. General features of reproduction of some congeneric species on Exogone

\begin{tabular}{|c|c|c|c|c|c|c|c|}
\hline & \multicolumn{2}{|c|}{ Swimming setae } & \multirow{2}{*}{$\begin{array}{l}\text { Eggs on } \\
\text { female }\end{array}$} & \multirow{2}{*}{$\begin{array}{c}\text { Juvenile on } \\
\text { parapodia }\end{array}$} & \multirow{2}{*}{$\begin{array}{l}\text { Fertilized } \\
\text { eggs internal }\end{array}$} & \multirow{2}{*}{$\begin{array}{c}\text { Juveniles } \\
\text { internal }\end{array}$} & \multirow[t]{2}{*}{ References } \\
\hline & & ㅇ & & & & & \\
\hline E. naidina & + & + & + & + & - & - & Thorson, 1946 \\
\hline E. verugera & + & + & + & + & - & - & Thorson, 1946 \\
\hline E. dispar & + & + & + & + & - & - & Pettibone, 1963 \\
\hline E. hebes & + & $?$ & + & $\begin{array}{l}\text { No observa- } \\
\text { tion recorded }\end{array}$ & - & - & $\begin{array}{l}\text { Mesnil and Caullery, } 1917 \\
\text { Fauvel, } 1923\end{array}$ \\
\hline E. hebes & + & - & - & - & + & + & This study \\
\hline
\end{tabular}


development exhibited by a species at any latitude (Strathmann and Strathmann, 1982).

Nonpelagic lecithotrophic development is nevertheless the most common form of development in cold water polychaetes. Low temperature and limited or irregular food supply require a greater effort on the part of the female to produce a relatively large yolky egg than under more favorable environmental conditions (Thorson, 1950). A form of brood protection provides the best possible chance for survival of individual offspring. Chances for transport into inhospitable environments are thus minimized and developing eggs and larvae are protected against infection and predation during vulnerable stages of development. Care of these eggs which are produced at such a high energetic cost is approached in various ways throughout the class. They may be laid in a gelatinous mass, singly or in groups attached to the substratum; they may be attached inside or outside the tube of the adult or they may be attached externally to the surface of the female or brooded internally (Schroeder and Hermans, 1975). Under these conditions the young usually hatch as juveniles or miniature adults capable of feeding themselves.

Brood protection by attachment of developing eggs to the females is often seen in the family Syllidae and internal brooding is now described for Exogone hebes. Viviparity within this species on the Grand Banks has obviously been a successful reproductive strategy and has perhaps been an ecological characteristic facilitating the numerical dominance of the benthos by this species in a more northern, colder part of its broad latitudinal range.

Acknowledgements. A. Diepenbrock, H. O'Connell, and S. Young kindly assisted with initial sample processing. We would like to thank Dr. K. Fauchald for allowing us access to the Smithsonian Institution collection for species verifications. Dr. C. M. Boyd kindly assisted with the electron microscopy. The numerous staff of MacLaren Plansearch, in particular Mr. P. Stewart, who assisted in the collection of the samples over many long cruises in 1980-81 are credited for helping to provide the material that made this paper possible. Constructive comments on the manuscript were provided by Mr. P. Stewart and Mr. K. Strong. The study was supported by Mobil Oil Canada Limited, Gulf Canada Resources Inc., Petro Canada Exploration Inc., Chevron Standard Ltd., and Columbia Gas Development Ltd. The Canadian Federation of University Women provided an Alice E. Wilson Grant which enabled P. Pocklington to visit the Smithsonian Institution.

\section{LITERATURE CITED}

Blake, J. A. (1969). Reproduction and larval development of Polydora from northern New England (Polychaeta: Spionidae). Ophelia 7: 1-63

Blake, J. A., Dean, D. (1973). Polychaetous annelids collected by the R/V HERO from Baffin Island, Davis Strait and West Greenland in 1968. Sth. Calif. Acad. Sci. Bull. 72: 31-39

Boesch, D., Kraeuter, J. N., Serafy, D. K. (1976). Draft benthic ecological studies: megabenthos and macrobenthos. In: Middle Atlantic Outer Continental Shelf Environmental Studies. Report to the Bureau of Land Management, Gloucester Point, Virginia. Chapter 6, p. 1-111

Caullery, M., Mesnil, F. (1916). Viviparité et parthengenese chez les Annelids polychètes: un nouveau Syllidien vivipare (Ehlersia nepiotoca, n. sp.). C. r. hebd. Séanc. Acad. Sci., Paris 163: 576-579

Chia, F.-S. (1970). Reproduction of arctic marine invertebrates. Mar. Pollut. Bull. 1: 78-79

Curtis, M. A. (1977). Life cycles and population dynamics of marine benthic polychaetes from the Disko Bay area of W. Greenland. Ophelia 16: 9-58

Daly, J. M. (1972). Maturation and breeding of Harmothoe imbricata (Polychaeta: Polynoidae). Mar. Biol. 12: 53-66

Fauvel, P. (1923). Polychètes errantes. Faune de France, Paris 5: $1-488$

Gibbs, P. E. (1968). A quantitative study of the polychaete fauna of certain fine deposits in Plymouth Sound. J. mar. biol. Ass. U.K. 49: 311-326

Hartman, O. (1951). Literature of the polychaetous annelids. Allan Hancock Foundation, University of Southern California, Los Angeles, California

Hutcheson, M. S., Stewart, P. L., Spry, J. M. (1981). The biology of benthic communities of the Grand Banks of Newfoundland (including the Hibernia area). In: Grand Banks Oceanographic Studies, Vol. 3. Final Report for Mobil Oil Canada Ltd. MacLaren Plansearch, Dartmouth, N. S.

Imajima, M. (1966). The Syllidae from Japan, 1 Exogoninae. Publs Seto mar. biol. Lab. 13: 385-404

Kinner, P., Maurer, D. (1978). Polychaetous annelids of the Delaware Bay region. Fish. Bull. U.S. 76: 209-224

Maurer, D., Kinner, P., Leathem, W., Watling, L. (1976). Benthic faunal assemblages off the Delmarva Peninsula. Estuar. coast. mar. Sci. 4: 163-177

Maurer, D., Leathem, W. (1980). Dominant species of polychaetous annelids of Georges Bank. Mar. Ecol. Prog. Ser. 3: 135-144

Mesnil, F., Caullery, M. (1917). Sur l' organization et la biologie d'un Syllidien [Exogone (Parexogone n.s.g.) hebes Webster \& Benedict. Var. hibernica Southern], habitant un sable compact. Bull. Soc. zool. Fr. 42: 126-132

Mileikovsky, S. A. (1971). Types of larval development in marine bottom invertebrates, their distribution and ecological significance: a re-evaluation. Mar. Biol. 10: 193-213

Pettibone, M. H. (1963). Marine polychaete worms of the New England region. 1. Aphroditidae through Trochochaetidae. Bull. U.S. natn. Mus. 227: 1-356

Schroeder, P. C., Hermans, C. O. (1975). Annelida; Polychaeta. In: Giese, A. C., Pearse, J. S. (eds.) Reproduction of marine invertebrates, Vol. III. Academic Press, New York, p. 1-213

Strathmann, R. R., Strathmann, M. F. (1982). The relationship between adult size and brooding in marine invertebrates. Am. Nat. 119: 91-101

Strong, K. (1981). Seasonal occurrence and distribution of zooplankton in waters over the Grand Banks of Newfoundland. In: Grand Banks Oceanographic Studies, Vol. 1. Final Report for Mobil Oil Canada Ltd. MacLaren Plansearch, Dartmouth, N. S.

Southern, R. (1914). Archiannelida and Polychaeta. Proc. R. Ir. Acad. 31: 1-160 
Thorson, G. (1946). Reproduction and larval development of Danish marine bottom invertebrates. Meddr Kommn Danm. Fisk.-og Havunders., Ser. Plankton 4: 1-523

Thorson, G. (1950). Reproduction and larval ecology of marine bottom invertebrates. Biol. Rev. 25: 1-45

Webster, H. E., Benedict, J. E. (1884). The Annelida Chaetopoda from Provincetown and Wellfleet, Mass. Ann. Rep. of the Comm. of Fish and Fisheries for 1881. 1. Government Printing Office, Washington
Wesenberg-Lund, E. (1947). Syllidae (Polychaeta) from Greenland waters. Meddr. Grønland 134: 1-38

Wesenberg-Lund, E. (1950a). Polychaeta. In: The Danish Ingolf Expedition, Vol. 4. Zoological Museum of the University, Copenhagen, p. 1-92

Wesenberg-Lund, E. (1950b). The Polychaeta of West Greenland. Meddr Grønland 151: 1-171

This paper was presented by Professor R. L. Haedrich; it was accepted for printing on January 6, 1983 